\title{
Dikaryon Formation in Coprinus cinereus: Selection and Identification of $B$ Factor Mutants
}

\author{
By R. W. HAYLOCK, ANDROULLA ECONOMOU AND \\ LORNA A. CASSELTON* \\ Department of Plant Biology and Microbiology, Queen Mary College, University of London, \\ Mile End Road, London El $4 N S$
}

(Received 28 April 1980)

\begin{abstract}
Mutations in the $B$ incompatibility factor of Coprinus cinereus were obtained using two techniques. Both selected for the expression of $B$-controlled functions (associated with nuclear migration during dikaryon morphogenesis) in heterokaryotic mycelia where these were blocked by having identical $B$ alleles present. The first technique selected for clamp cell fusion in a common $B$ heterokaryon, the second selected for septum dissolution in a heterokaryon following a common $B$ mating. Two mutants, one derived by each of the selection techniques, were studied in detail. In both, mutation was inseparable by recombination from the $B$ locus and resulted in self-compatibility. Mutant monokaryons had uninucleate cells and intact septa. Thus, full regulatory control of morphogenesis in the mutant monokaryon was maintained. However, both mutations promoted clamp cell fusion in dikaryons formed between the mutants and monokaryons having the progenitor $B$ allele or the mutant self allele. Therefore, mutation leads to the loss of regulation of clamp cell fusion. A combination of a $B$ mutation and an $A$ mutation ( $A m u t B m u t$ ) in the same nucleus gave a haploid mycelium which resembled a true dikaryon; thus, both the $A$ and $B$ morphogenetic sequences which are expressed in the dikaryon were operating. However, these dikaryons were not fertile.
\end{abstract}

\section{INTRODUCTION}

The conversion of a uninucleate-celled monokaryotic mycelium into a dikaryon with regular binucleate cells and clamp connexions is a characteristic feature of many basidiomycete life cycles. The dikaryon is the prerequisite for sexual reproduction since it is usually only on this mycelium that the fruit bodies develop. Basidiomycetes have no specialized sexual cells and the genes which control sexual compatibility do so by regulating the morphogenetic sequence leading to dikaryon formation (see Casselton, 1978).

In tetrapolar species, such as Coprinus cinereus and Schizophyllum commune, there are two incompatibility factors, $A$ and $B$, each with many allelic specificities. They are referred to as factors rather than genes because, in Schizophyllum at least, both $A$ and $B$ derive their specificity from alleles at two closely linked genes $\alpha$ and $\beta$ (see Raper, 1966). $A$ and $B$ each control part of the morphogenetic sequence leading to dikaryon formation. For two monokaryons to be compatible, alleles of both $A$ and $B$ must be different. If mated monokaryons have a common $A$ or $B$ allele a sterile heterokaryon can be established which exhibits only part of the morphogenetic sequence. From a study of such heterokaryons it is evident that the $A$ factor controls clamp cell formation and synchronized nuclear division in the hyphal tip cells whereas the $B$ factor controls events associated with nuclear migration (Swiezynski \& Day, $1960 a, b$; Raper, 1966). 
The $B$ factor promotes dissolution of the complex dolipore septa to allow extensive migration of nuclei through established monokaryotic cells at the onset of dikaryotization (Giesy \& Day, 1965). It also promotes fusion of the clamp cell following apical cell division in the dikaryon since it is through the clamp that one of the tip cell nuclei must migrate into the subapical cell.

The $A$ and $B$ factors are considered to have a regulatory role in morphogenesis (Raper, 1966). This is evident from a study of the effect of mutation in either of the factors in Schizophyllum. Mutation generally leads to self-compatibility and concomitant with this is a switching on of the morphogenetic sequence controlled by the factor which is mutated (Parag, 1962; Raper et al., 1965; Koltin, 1968). Thus, monokaryons with a mutated $A$ factor mimic heterokaryons which have different $A$ factors but common $B$ factors (common $B$ heterokaryons). In both mycelia the clamp cell develops and a synchronized nuclear division occurs but the clamp cell cannot fuse and retains a trapped nucleus. Monokaryons with a mutated $B$ factor are similar to heterokaryons with different $B$ factors and common $A$ factors (common $A$ heterokaryons) and both exhibit continuous septum dissolution (Niederpruem, 1969; Koltin \& Flexer, 1969). The combination of an $A$ factor and a $B$ factor mutation within the same nucleus leads to operation of the complete morphogenetic sequence to give a sexually fertile mycelium which resembles the dikaryon(Raper et al., 1965).

Although $A$ factor mutants of Coprinus have been described (Day, 1963), $B$ factor mutants have not previously been obtained. The present report describes the isolation and characterization of two $B$ mutants. These are of particular interest because, unlike the analogous mutants in Schizophyllum, they have not lost regulatory control in the monokaryon as a result of mutation to self-compatibility. This points to intrinsic differences in incompatibility control in the two fungi which may relate to basic differences in cellular metabolism.

\section{METHODS}

Strains. Wild-type stocks were H1 $A 5 B 5, \mathrm{H} 9 A 6 B 6, \mathrm{H} 2 A 6 B 5, \mathrm{H} 5 A 5 B 6, \mathrm{TC} 4 A 5 B 5$ and TC10 $A 6 B 5$. Auxotrophic mutants with appropriate mating types were used to construct common $B$ matings and common $B$ heterokaryons with complementing markers. The following mutations were involved: $a d-2, a d-5, a d-8$ and $a d-9$ each causing a growth requirement for adenine; met-1, met-5 and met-9 each causing a growth requirement for methionine. The $A$ mutant strain E117,9 ( $A 6$ mut ad-8 B5) was kindly sent to us by Dr P. R. Day, and a derivative of this, A125 (A6mut B5) was used to construct the Amut Bmut strains referred to in the text.

Media. The minimal medium was that used by Shahriari \& Casselton (1974). When required, supplements of L-methionine $\left(100 \mathrm{mg} \mathrm{l}^{-1}\right)$ and adenine sulphate $\left(100 \mathrm{mg} \mathrm{l}^{-1}\right)$ were added before autoclaving. Complete medium was modified from that of Lewis (1961) with glucose decreased to $1.0 \%(w / v)$ and addition of $0.025 \%(\mathrm{w} / \mathrm{v}) \mathrm{MgSO}_{4} .7 \mathrm{H}_{2} \mathrm{O}$.

Mycelial cultures. These were routinely grown at $37^{\circ} \mathrm{C}$ in the dark.

Fruiting. Heterokaryons and dikaryons were inoculated to sterile horse dung and incubated in the light at $26^{\circ} \mathrm{C}$.

Mutagenesis treatment. For u.v. irradiation, a Hanovia model II low pressure mercury discharge tube was used. The surfaces of $5 \mathrm{~d}$-old plate cultures of common $B$ heterokaryons were irradiated for 7.5 and 15 min. Cultures were kept in the dark for $12 \mathrm{~h}$ to prevent photoreactivation and then inocula were transferred to horse dung. For $N$-methyl- $N^{\prime}$-nitro- $N$-nitrosoguanidine treatment, the mutagen was incorporated into solid medium at a concentration of $100 \mu \mathrm{g} \mathrm{ml}^{-1}$.

Cytology. Nuclear distribution and clamp cell fusions were examined in Giemsa-stained material using a method based on that of Van de Valk \& Wessels (1973). Mycelia were grown on dialysis membrane over solid medium. Material, still attached to the membrane, was fixed in methanol/acetic acid $(3: 1, \mathrm{v} / \mathrm{v})$ for at least $24 \mathrm{~h}$ at $4{ }^{\circ} \mathrm{C}$. Hydrolysis in $3 \mathrm{M}-\mathrm{HCl}$ for $30 \mathrm{~min}$ was followed by washing three times in water and once in $0.005 \mathrm{M}$-phosphate buffer $\mathrm{pH} \mathrm{6.8,} \mathrm{before} \mathrm{transfer} \mathrm{to} \mathrm{a} 1 \%$ solution of Giemsa stain in the same buffer. Material was stained for at least $2 \mathrm{~h}$.

Electron microscopy. Material was grown for 3 to $4 \mathrm{~d}$ on dialysis membrane over solid medium. Samples were fixed in $4.0 \%(\mathrm{w} / \mathrm{v})$ glutaraldehyde in $0.2 \mathrm{M}$-cacodylate buffer $\mathrm{pH} 7.0$, followed by post-fixation in $2 \%$ (w/v) osmium tetroxide. All procedures were as described by Casselton \& Kirkham (1975). Sections were stained with lead citrate and examined in a Jeol $100 \mathrm{C}$ electron microscope. 


\section{RESULTS}

\section{Selection for mutation in the $B$ factor}

Two techniques have been used to select for mutation in the $B$ factor, both designed to select for expression of $B$ functions in a mycelium in which these were blocked by having only nuclei with the same $B$ allele.

Selection for clamp cell fusion in common $B$ heterokaryons. The common $B$ heterokaryon, with unfused clamp cells, is normally sexually sterile. The development of fertile fruit bodies following mutagen treatment is indicative of mutation in one of the common $B$ factors to create a new $B$ specificity compatible with the original $B$ factor. This allows clamp cell fusion and normal dikaryon development. This is the only selection technique which has been used previously and it has yielded many $B$ factor mutants of Schizophyllum (Parag, 1962; Raper et al., 1965; Koltin \& Raper, 1966; Koltin, 1968; Raudaskoski et al., 1976). Previous attempts to obtain $B$ factor mutants of Coprinus in this way were unsuccessful because heterokaryons fruited without mutation in $B$ (Swiezynski \& Day, $1960 a$; P. R. Day, personal communication).

Several balanced common $B$ heterokaryons were constructed for the present work. These were exposed to u.v. irradiation before being transferred to conditions which promote fruiting. Some 40 fruit bodies developed within 18 to $28 \mathrm{~d}$. Samples of basidiospores from five different genetic backgrounds were analysed to check for a normal segregation of markers and a possible new $B$ factor specificity. The results of six of these analyses are given in Table 1.

In all cases there was the expected segregation of auxotrophic markers showing that the two component nuclei had fused and undergone a normal meiosis. No new $B$ specificity was detected in any of the samples; thus all fruit bodies developed on common $B$ heterokaryons. The conditions which promote this fruiting on common $B$ heterokaryons are not understood. A subsequent attempt to fruit these same common $B$ heterokaryons under similar conditions yielded just a single fruit body after a much longer period ( $74 \mathrm{~d})$ and this proved to be the result of a $B$ factor mutation. Evidence for this is presented below.

Selection for septum dissolution and nuclear migration. This is a new technique which we have devised. Common $B$ matings between monokaryons having complementary auxotrophic mutations were set up on membranes placed over supplemented medium containing $N$-methyl- $N^{\prime}$-nitro- $N$-nitrosoguanidine. When the mycelia had grown together, the membranes were transferred to minimal medium on which neither monokaryon could grow. Cultures were left for $10 \mathrm{~d}$ and then examined for development of prototrophic growth. Prototrophic common $B$ heterokaryons developed on most cultures and this could readily be distinguished because it grew out only at the junction where the two monokaryons had met. Of special interest was the prototrophic growth which developed on a few cultures at the periphery of one of the monokaryons since this was dikaryon. For a dikaryon to occur in this region a nucleus must have migrated from one monokaryon through the cells of the other and this would only be possible if mutation had given rise to a new $B$ specificity which would promote septum dissolution.

From a total of 1000 membrane matings, five prototrophic dikaryons were obtained which fruited and yielded basidiospore progeny with a new $B$ factor specificity. One of these mutants was chosen for further study and comparison with the mutant obtained by the first technique.

\section{Genetic analyses with $B$ mutants}

The two mutations were derived in strains having different $B$ alleles $-B 5$ in the case of the first technique used and $B 6$ in the case of the second.

Location of mutations in the $B$ factor. To determine whether mutation was in the $B$ factor 
(5)

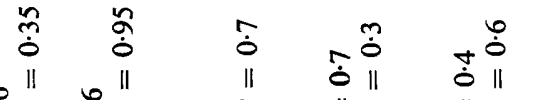

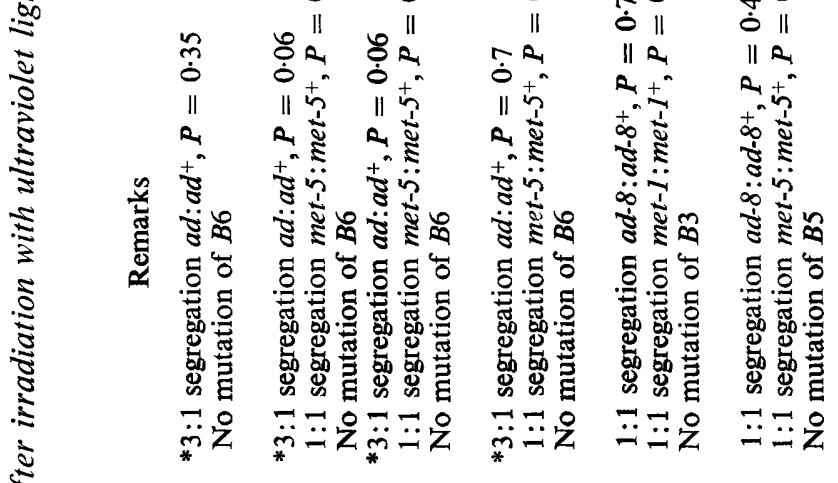

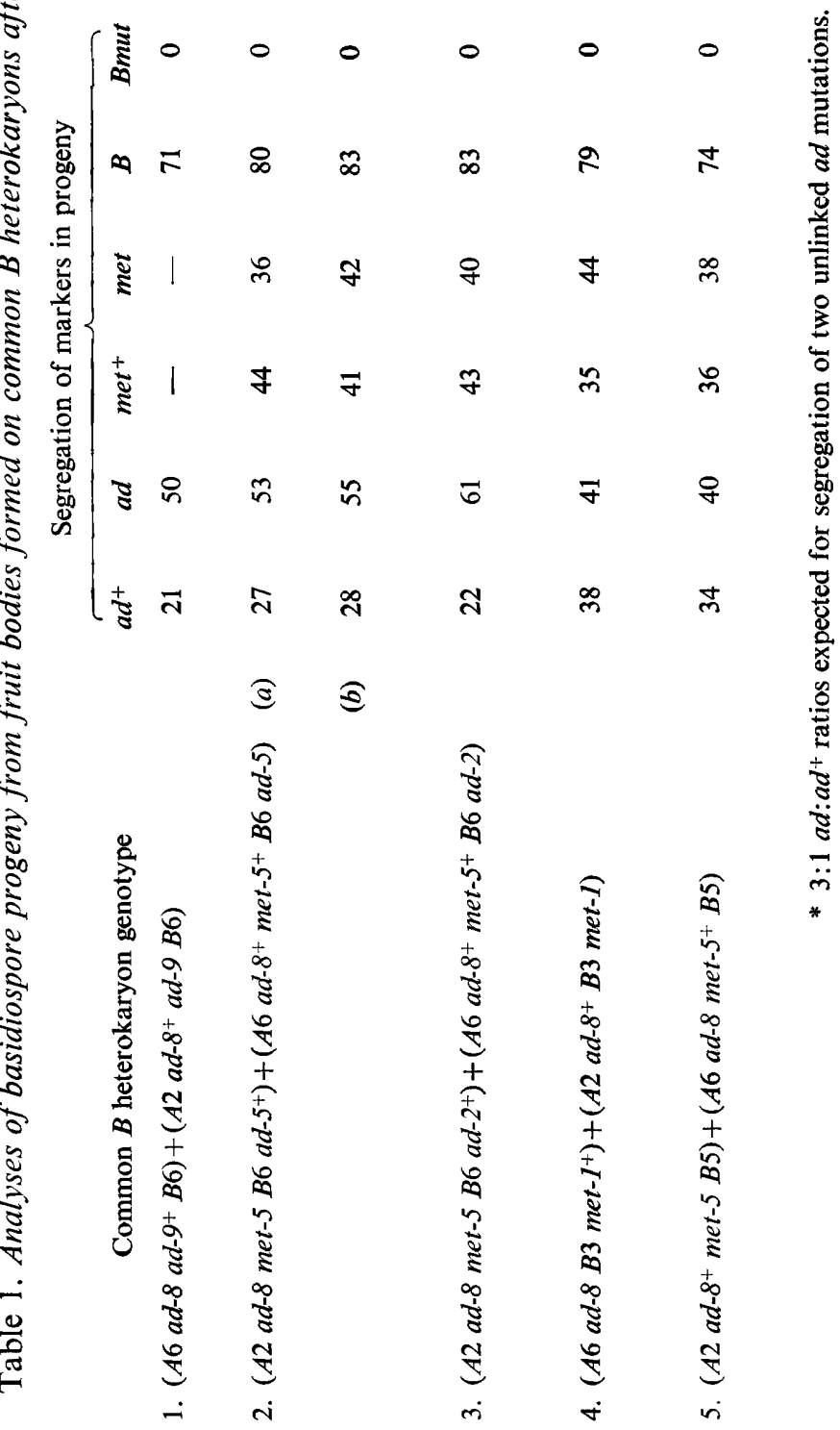




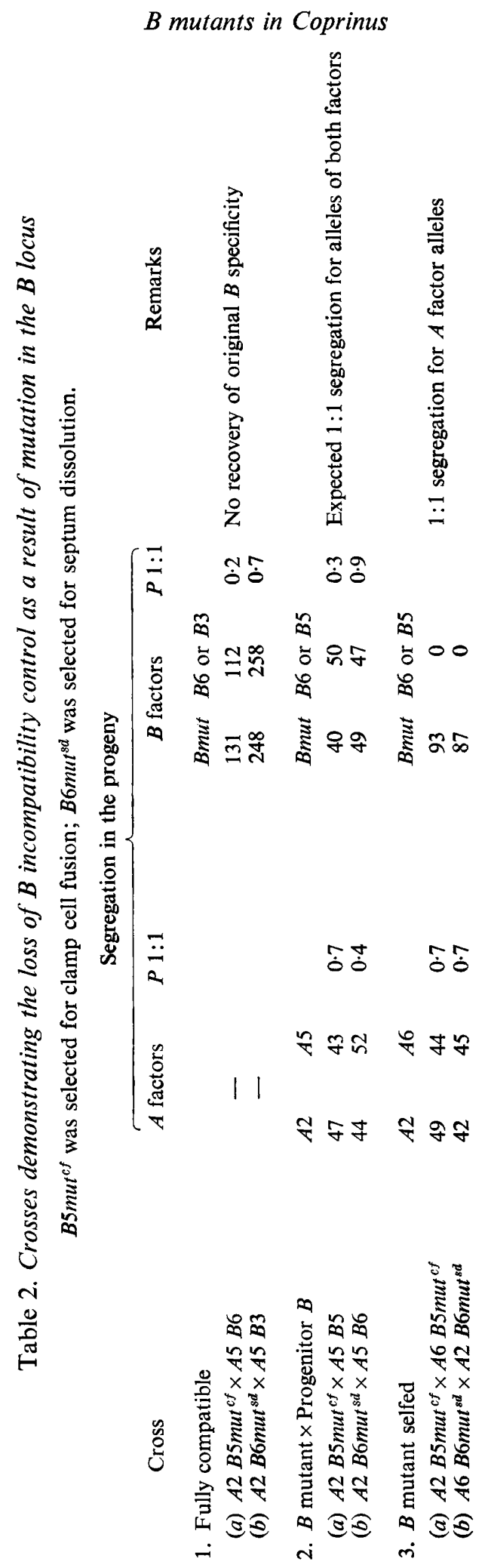


Table 3. Effect of mutation in the B locus on clamp cell fusion

\begin{tabular}{|c|c|c|c|c|}
\hline \multirow[b]{2}{*}{ Mycelium } & \multicolumn{2}{|c|}{ False clamps } & \multicolumn{2}{|c|}{ True clamps } \\
\hline & No. & $\%$ & No. & $\%$ \\
\hline $\begin{array}{l}\text { d factors } \\
\text { on } A 6 B 5+A 5 B 6\end{array}$ & 103 & $15 \cdot 0$ & 583 & 85.0 \\
\hline $\begin{array}{l}\text { on } B \text { heterokaryon } \\
A 2 B 5+A 5 B 5 \\
A 6 B 6+A 2 B 6\end{array}$ & $\begin{array}{l}181 \\
318\end{array}$ & $\begin{array}{l}90 \cdot 5 \\
88 \cdot 1\end{array}$ & $\begin{array}{l}19 \\
43\end{array}$ & $\begin{array}{r}9.5 \\
11.9\end{array}$ \\
\hline
\end{tabular}

B. Mutated $B$ factors

1. Fully compatible

(a) $A 2 B 5 m u t^{c f}+A 6 B 6$

(b) $A 6 B 6 m u t^{s d}+A 5 B 5$

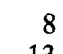

13

2. $B$ mutant $\times$ Progenitor $B$

(a) $A 2 B 5 m u t^{n f}+A 5 B 5$

(b) $A 6 B 6 m u t^{s d}+A 5 B 6$

3. $B$ mutant selfed

(a) $A 2 B 5 m u t^{c f}+A 5 B 5 m u t^{c f}$

(b) $A 6 B 6 m u t^{s d}+A 2 B 6 m u t^{s d}$

C. Monokaryons with mutated A factor

1. $A$ mutation only

A6mut B5

2. $A$ and $B$ mutations

(a) $A 6$ mut $B 5 m u t^{c f}$

(b) A6mut B6mut ${ }^{s d}$

\section{2}

196

21

93

130

17

245
$4 \cdot 0$

6.5

$11 \cdot 0$

$50 \cdot 7$

$10 \cdot 5$

$31 \cdot 0$

$82 \cdot 8$

$13 \cdot 5$

$48 \cdot 0$
192

187

$96 \cdot 0$

$93 \cdot 5$

$89 \cdot 0$

$49 \cdot 3$

$89 \cdot 5$

$69 \cdot 0$

$\begin{array}{ll}179 & 89 \cdot 5 \\ 207 & 69 \cdot 0\end{array}$

or in another gene, each mutant was crossed to a monokaryon having a different $B$ allele from the progenitor allele and the progeny were tested for $B$ allele segregation. If mutation was within the $B$ factor then a 1:1 segregation for the mutated allele and wild-type allele would be observed. If mutation was at another locus then, as a result of recombination, some of the progeny would exhibit the original $B$ allele specificity ( $B 5$ or $B 6$ depending on the mutant strain).

The results of these two crosses are shown in Table 2(1). From neither cross was the original unmutated $B$ allele recovered and the $1: 1 B$ allele segregations observed were those expected for mutations within or very close to the $B$ factor.

No attempt was made to locate the mutations more precisely because there are no gene markers close to $B$ and the structure of the $B$ factor itself has not yet been resolved. A total of 5289 progeny from a cross involving $B 5$ and $B 6$ (the two $B$ alleles of interest) were analysed but no recombinant $B$ specificity was detected. Day (1960) also failed to detect recombination between these two alleles. However, not all $\alpha \beta$ combinations of $B$ recombine in Schizophyllum (Koltin et al., 1967) so a more extensive testing of different alleles in Coprinus is still required to establish whether or not there are two distinct loci.

The two mutations have been designated $B 5 m u t^{e f}$ and $B 6 m u t^{s d}$. The suffix $c f$ or $s d$ denotes the technique by which the mutation was selected, i.e. $c f$ selected for expression of clamp cell fusion and $s d$ selected for expression of septum dissolution.

Loss of incompatibility control. If compatibility is considered in terms of sexual reproduction, then normal fruiting and meiosis can be considered as criteria of the compatibility of two nuclei. The mutants were each crossed to a strain carrying the unmutated progenitor $B$ allele and also to a strain (recombinant for $A$ ) carrying the same mutant $B$ allele. In all cases an apparently normal dikaryon developed which fruited within the normal period of 10 to $14 \mathrm{~d}$. The data presented in Table $2(2,3)$ shows that the $A$ and $B$ alleles segregated exactly as expected from a normal meiosis. 

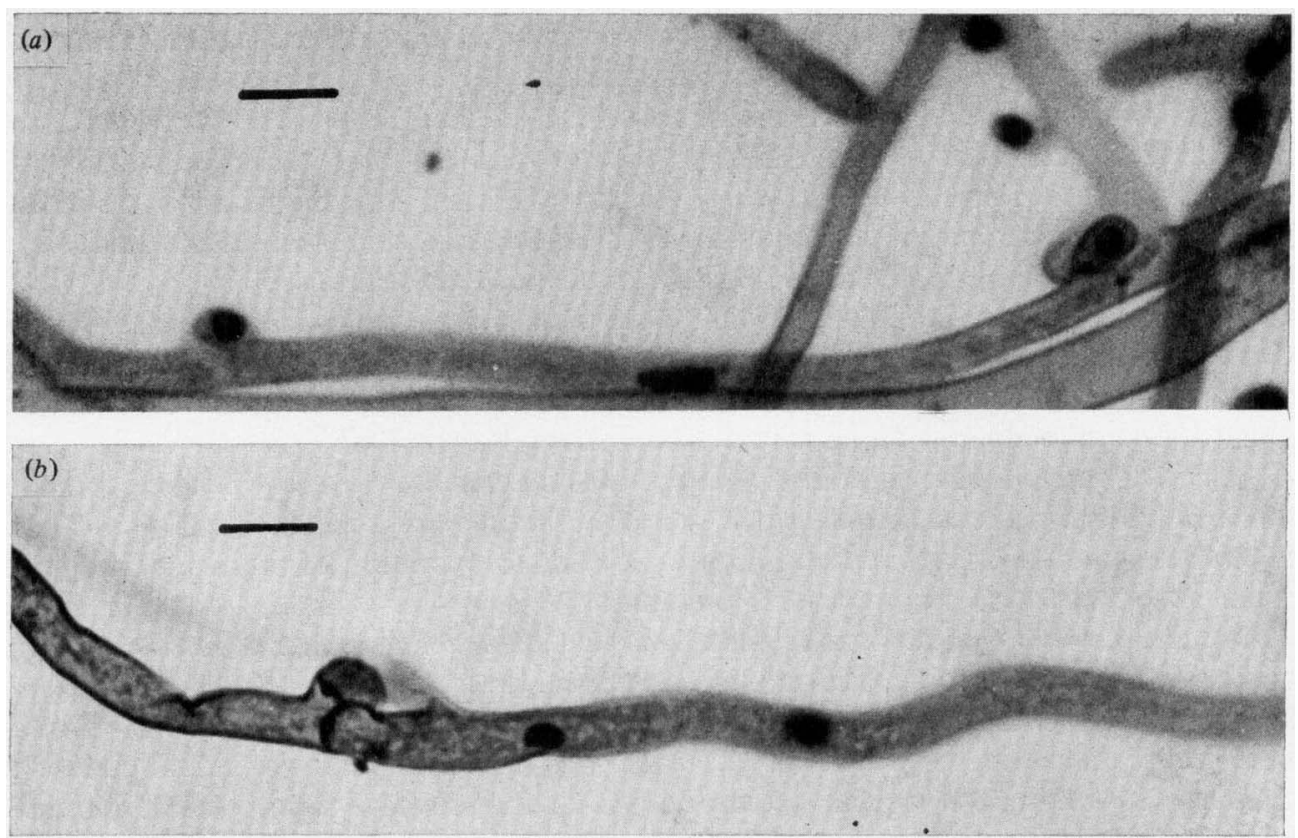

Fig. 1. Effect of mutation in the $B$ factor on clamp cell fusion in a monokaryon with a mutated $A$ factor. (a) Amut monokaryon which mimics a common $B$ heterokaryon: uninucleate cell and unfused clamp cells each containing a trapped nucleus. (b) Amut Bmut ${ }^{\text {cf }}$ double mutant which mimics a dikaryon: typical cell with two nuclei and fused clamp cell. Bar markers represent $10 \mu \mathrm{m}$.

Thus, in both mutants mutation in the $B$ factor leads to self-compatibility. (Selfcompatibility refers only to the $B$ factor, not to the individual monokaryon because alleles at both $A$ and $B$ loci must be compatible for dikaryon formation.)

\section{Effect of $B$ mutation on morphogenesis}

Septum dissolution. In Schizophyllum, mutation in the $B$ factor switches on $B$-controlled morphogenesis. The dolipore septa of the mutant monokaryon are dissolved and there is continuous migration of nuclei so that their distribution in the cells is irregular. $B$ mutant strains also have a characteristic unilateral mating behaviour in that the mutant can only donate nuclei to a compatible monokaryon and cannot itself accept nuclei (Parag, 1962; Raper, 1966; Niederpruem, 1969; Koltin \& Flexer, 1969).

Cytological and electron microscopic studies of both the $B$ mutant strains of Coprinus revealed a quite different situation from that found in Schizophyllum. The cells were predominantly uninucleate and had intact dolipore septa. There was, therefore, no expression of $B$ factor-controlled morphogenesis in these $B$ mutant monokaryons indicating that the regulatory function of the mutated $B$ factors with respect to septum dissolution was unimpaired. In addition, both $B$ mutants behaved like normal monokaryons and exhibited a bilateral mating behaviour, donating and accepting nuclei in all matings.

Clamp cell fusion. The development of the clamp cell in the dikaryon is controlled by the $A$ factor but its fusion is controlled by the $B$ factor. In order to assess the effect of $B m u t$ on clamp cell fusion all mycelia to be examined were fixed and stained. True (fused) and false (unfused) clamp cells were distinguished by whether or not they contained a nucleus. The results are given in Table 3.

Clearly, a number of clamps, even in compatible situations, will be in the process of fusing and therefore still contain a nucleus. Extensive observation of a normal dikaryon showed that as many as $15 \%$ of the clamps may be in this state. However, this is quite 
different from the common $B$ heterokaryon where $B$ function is blocked and some $90 \%$ of the clamps were classified as unfused (Table $3 \mathrm{~A}$ ).

As expected, $B m u t$ in combination with a wild-type $B$ allele different from the progenitor allele led to formation of a normal dikaryon with over $90 \%$ fused clamp cells. It is in the common $B$ associations (Table $3 \mathrm{~B}$ ) where $B m u t$ was present with the wild-type progenitor allele or with the mutant self allele that the effect of Bmut on clamp cell fusion can be seen. Both $B$ mutations led to a significant increase in the percentage of fused clamp cells. It was, however, interesting to find that they differed in the degree to which they promoted fusion. $B 5 m u t^{\text {cf }}$ promoted $89 \%$ fusion of the clamp cells, a level indistinguishable from that seen in a normal dikaryon, whereas $B 6 m u t^{s d}$ promoted only 49 to $69 \%$ fusion, a level comparable to that found in analogous mutants in Schizophyllum (Raper, 1966).

The activity of Bmut in promoting clamp cell fusion can also be seen when it is combined with a mutation in the $A$ factor, Amut. $A$ mutant strains are available in Coprinus (Day, 1963) and, as in Schizophyllum, mutation in $A$ leads to operation of the $A$ morphogenetic sequence so that these strains resemble common $B$ heterokaryons in producing unfused clamp cells. An $A 6 m u t$ strain was crossed to both a $B 5 m u t^{t f}$ and a $B 6 m u t^{s d}$ strain and from each cross progeny with a typical dikaryotic appearance were recovered. Examination of the clamp cells (Table $3 \mathrm{C}$ ) showed that each $B$ mutation had promoted fusion of the clamp cells; the level to which this occurred was exactly similar to that found in the 'common $B$ ' matings. A typical dikaryotic cell of the $A 6 m u t B 5 m u t^{c f}$ double mutant is shown in Fig. 1, together with the typical common $B$ morphology of the Amut monokaryon.

Despite the fact that both $A$ and $B$ morphogenetic sequences were operating to give a dikaryotic morphology in the Amut Bmut mycelia, none of the isolates tested were fertile. All strains were prototrophic so that this was not due to a growth requirement. Numerous fruit body initials developed and even differentiated, but failed to expand into mature fruit bodies.

\section{DISCUSSION}

The two techniques described have each yielded mutations which map in, or close to, the $B$ locus of Coprinus cinereus. The two mutations chosen for study, one obtained by each technique, are similar in that they affect both functions assigned to the incompatibility locus - self-recognition and regulation of the genes involved in dikaryon morphogenesis.

Both mutations lead to self-compatibility so that the mutated $B$ allele is compatible with itself and with its unmutated progenitor $B$ allele. Compatibility is expressed by the ability to form normal or near normal dikaryons with the subsequent development of fertile fruit bodies. To form a dikaryon the clamp cells must fuse and since the genes responsible for this are regulated by the $B$ factor it is evident that mutation to self-compatibility leads to loss of regulatory control of clamp cell fusion. It is interesting that the mutations can differ in the extent to which they cause loss of regulatory control. This may be a reflection of the different techniques used to select them. B5mut ${ }^{\text {of }}$ was selected for its ability to promote clamp cell fusion and this mutation results in a complete loss of regulatory control, whereas with the $B 6 m u t^{8 d}$ mutation only 50 to $70 \%$ of the clamps are fused suggesting a partial loss of regulation.

The Amut Bmut double mutants had both the $A$ and $B$ morphogenetic sequences operating constitutively to give the dikaryotic morphology. Failure of these to fruit was unexpected since analogous mutants in Schizophyllum are fertile, but it must be remembered that although the dikaryon is the normal prerequisite for fruit body development, other genes control the ability to fruit (Stahl \& Esser, 1976). The isolates tested may not have been genetically competent to fruit despite having, in some cases, a completely normal dikaryotic morphology.

In Schizophyllum, all mutations within $B$ which result in self-compatibility not only 
switch on clamp cell fusion in the dikaryon but also lead to constitutive septum dissolution and nuclear migration in the monokaryon. In contrast, we find that this part of the $B$ controlled morphogenetic sequence is not switched on by either of the Coprinus mutations. $B$ mutant monokaryons have uninucleate cells with intact dolipore septa and exhibit normal bilateral mating behaviour.

It is evident that self-compatibility of $B$ mutants is not dependent on a constitutive operation of the $B$-controlled morphogenetic sequence in the monokaryon. This is also true in Schizophyllum and it seems more likely that the constitutive operation of septum dissolution in this fungus is a secondary rather than a primary effect of mutation in $B$. Incompatibility can in fact be separated from the regulation of septum dissolution by mutations located in the $B$ loci or at a closely linked site which result in constitutive septum dissolution without a change to self-compatibility (Koltin, 1968; Raudaskoski et al., 1976). Moreover, in the initial stages of growth, $B$ mutants of both Schizophyllum and Coprinus are similar. Parag (1962) recognized that in germinating basidiospores of $S$ chizophyllum, B mutants initially had the appearance and bilateral mating behaviour of typical non-mutant monokaryons. Koltin \& Flexer (1969) showed that this normal monokaryotic behaviour coincided with a period of about $50 \mathrm{~h}$ when the cells were uninucleate and the dolipore septa were still present. Clearly, in both fungi mutant self alleles can interact like two non-allelic wild-type $B$ factors to promote the normal septal dissolution which precedes migration of donor nuclei in a bilateral mating. This condition persists in $B$ mutant mycelia of Coprinus, but in Schizophyllum there is a sudden switch to constitutive septum dissolution with concomitant nuclear migration and unilateral mating behaviour. There are reasons for suggesting that this switch is the result of a major change in cellular metabolism in Schizophyllum which is not typical for other basidiomycetes.

The $B$ mutant of Schizophyllum and the common $A$ heterokaryon which it mimics both have an aberrant morphology with no aerial mycelium and distorted hyphal walls; this is not typical of common $A$ mycelia of Coprinus or of two other tetrapolar basidiomycetes which have been studied, Polyporus ciliatus and Agrocybe aegerita (Stahl \& Esser, 1976; Esser et al., 1974). The aberrant morphology in Schizophyllum can be attributed to elevated levels of an enzyme(s) R-glucanase which hydrolyses the alkali-resistant R-glucan component of the cell wall (Wessels, 1965, 1969; Wessels \& Niederpruem, 1967). R-glucan acts as a storage carbohydrate but is not normally mobilized in the monokaryon. Casselton (1978) has suggested that its mobilization in common $A$ heterokaryons and $B$ mutants may be due to another abnormal property of these mycelia, an impairment in energy conservation (Hoffman \& Raper, 1974), which results in inefficient utilization of carbohydrate from the medium. R-glucanase has been implicated in septum dissolution (Janszen \& Wessels, 1970) so that widespread dissolution of septa would be expected in $B$ mutant mycelia with elevated levels of the enzyme, but this could well be an atypical expression of the $B$ control of incompatibility. We have found (R. W. Haylock \& L. A. Casselton, unpublished results) that a similar enzyme is implicated in septum dissolution in Coprinus but even when septum dissolution does occur as in the common $A$ heterokaryon, its level is not elevated and we have not observed any of the other abnormalities in cellular metabolism characteristic of Schizophyllum.

From the present work we can draw the following conclusion about the control of incompatibility by the $B$ factor. Clamp cell fusion in the dikaryon and septum dissolution in the monokaryon are regulated separately. The regulation of clamp cell fusion is lost and the strain becomes self-compatible as a result of mutation. This indicates that the same $B$ factor product is concerned with incompatibility and the regulation of genes which control the clamp cell fusion part of the $B$ morphogenetic sequence. However, regulation of the genes which bring about septum dissolution can be maintained when strains become selfcompatible and must be controlled by a different gene which is also part of the $B$ factor complex. 
R. W. Haylock gratefully acknowledges the receipt of a research studentship from the Science Research Council.

\section{REFERENCES}

Casselton, L. A. (1978). Dikaryon formation in the higher basidiomycetes. In The Filamentous Fungi, vol. 3, pp. 278-297. Edited by J. E. Smith \& D. R. Berry. London: Arnold.

Casselton, L. A. \& KirkhaM, J. B. (1975). Growth and ultrastructural studies on the mitochondrial mutant of Coprinus lagopus. Archives of Microbiology 106, 215-220.

DAY, P. R. (1960). The structure of the $A$ mating type locus in Coprinus lagopus. Genetics 45, 641-650.

DAY, P. R. (1963). Mutations of the $A$ mating type factor in Coprinus lagopus. Genetical Research 4, 55-64.

Esser, K., Semerdzieva, M. \& Stahl, U. (1974). Genetische Untersuchungen an dem Basidiomyceten Agrocybe aegerita. 1. Eine Korrelation zwischen dem Zeitpunkt der Fruchtkorperbildung und monokaryotischem Früchten und ihre Bedeutung für Züchtung und Morphogenese. Theoretical and Applied Genetics 45, 77-85.

GIESY, R. M. \& DAY, P. R. (1965). The septal pores of Coprinus lagopus in relation to nuclear migration. American Journal of Botany 52, 287-293.

Hoffman, R. M. \& RAPER, J. R. (1974). Genetic impairment of energy conservation in development of Schizophyllum. Efficient mitochondria in energy-starved cells. Journal of General Microbiology 82, 67-75.

J ANSzen, F. H. A. \& Wessels, J. G. H. (1970). Enzymatic dissolution of hyphal septa in a basidiomycete. Antonie van Leeuwenhoek 36, 255-257.

KoltiN, Y. (1968). The genetic structure of the incompatibility factors of Schizophyllum commune: comparative studies of primary mutations in the $B$ factor. Molecular and General Genetics 102, 196-203.

Koltin, Y. \& Flexer, A. S. (1969). Alteration of nuclear distribution in $B$ mutant strains of Schizophyllum commune. Journal of Cell Science 4, 739-747.

Koltin, Y. \& RAPER, J. R. (1966). Schizophyllum commune: new mutations in the $B$ incompatibility factor. Science 154, 510-511.

Koltin, Y., Raper, J. R. \& Simchen, G. (1967). The genetic structure of the incompatibility factors of Schizophyllum commune: the $B$ factor. Proceedings of the National Academy of Sciences of the United States of America 57, 55-62.

LEwIS, D. (1961). Genetic analysis of methionine suppressors in Coprinus. Genetical Research 2, $141-155$.

NiederPruem, D. J. (1969). Direct studies of nuclear movements in Schizophyllum commune. Archiv für Mikrobiologie 64, 387-395.

Parag, Y. (1962). Mutations in the $B$ incompatibility factor of Schizophyllum commune. Proceedings of the National Academy of Sciences of the United States of America 48, 743-750.

RAPER, J. R. (1966). Genetics of Sexuality in Higher Fungi. New York: The Ronald Press Co.

RAPER, J. R., Boyd, D. H. \& RAPER, C. A. (1965). Primary and secondary mutations at the incompatibility loci in Schizophyllum. Proceedings of the National Academy of Sciences of the United States of America 53, 1324-1332.

Raudaskoski, M., Stamberg, J., Bawnik, N. E. \& KoLTIN, Y. (1976). Mutational analysis of natural alleles at the $B$ incompatibility factor of Schizophyllum commune: $\alpha 2$ and $\beta 6$. Genetics $83,507-516$.

Shahriari, H. \& Casselton, L. A. (1974). Suppression of methionine mutants in Coprinus. 1. Complementation and allele specificity as criteria of suppressor gene action. Molecular and General Genetics 134, 85-92.

STAHL, U. \& ESSER, K. (1976). Genetics of fruit body production in higher basidiomycetes. 1. Monokaryotic fruiting and its correlation with dikaryotic fruiting in Polyporus ciliatus. Molecular and General Genetics 148, 183-197.

SwiezYNSKI, K. M. \& DAY, P. R. (1960a). Heterokaryon formation in Coprinus lagopus. Genetical Research 1, 114-128.

SWIEZYNSKI, K. M. \& DAY, P. R. (1960 b). Migration of nuclei in Coprinus lagopus. Genetical Research 1, 129-139.

VAN de Valk, P. \& Wessels, J. G. H. (1973). Mitotic synchrony in multinucleate Schizophyllum protoplasts. Protoplasma 78, 427-432.

Wessels, J. G. H. (1965). Morphogenesis and biochemical processes in Schizophyllum commune Fr. Wentia 13, 1-113.

Wessels, J. G. H. (1969). Biochemistry of sexual morphogenesis in Schizophyllum commune: effect of mutations affecting the incompatibility system on cell wall metabolism. Journal of Bacteriology 98, 697-704.

Wessels, J. G. H. \& Niederpruem, D. J. (1967). Role of a cell wall glucan degrading enzyme in mating of Schizophyllum commune. Journal of Bacteriology 94, 1594-1602. 